\title{
Pain management programme for Chinese patients: a 10-year outcome review
}

\author{
MC Chu *, Rainbow KY Law, Leo CT Cheung, Marlene L Ma, Ewert YW Tse, Tony CM Wong, PP Chen
}

\section{A B S T R A C T}

Objectives: To review the clinical and social benefits of a pain management programme in Hong Kong.

Design: Prospective cohort study.

Setting: Tertiary out-patient clinic, Hong Kong.

Participants: Patients with chronic non-cancer pain and prolonged (mean, 46 months) psychosocial disability who joined the Comprehensive Outpatient Pain Engagement programme between 2002 and 2012.

Intervention: A structured 6-week out-patient pain rehabilitation course designed to improve function and reduce disability, regardless of the cause or severity of pain.

Main outcome measures: Social outcomes included return-to-work rate, hospital admissions, and outpatient visits. Physical outcomes included tolerance to sitting and standing. Psychological constructs such as mood, catastrophisation, self-efficacy, quality of life, and perceived performances were used. Each measure was taken before and 1 year after the programme.

Results: There was significant increase in returnto-work rate 1 year after commencement of the programme (35\% after vs $17 \%$ before the programme; odds ratio $=3.01)$, reduction in medical utilisation, and improvement in all physical and psychological measures. Pain intensity, psychological distress, and of pain and higher physical functioning score in 36-Item Short-Form Health Survey were prognostic indicators.

Conclusions: Patients with chronic pain who joined the Comprehensive Outpatient Pain Engagement programme showed significant functional improvement despite the long history of pain.

Hong Kong Med J 2015;21:304-9

DOI: $10.12809 / \mathrm{hkmj} 144350$

\author{
MC Chu *, FFPMANZCA \\ ${ }^{2}$ RKY Law, MPhil \\ ${ }^{3}$ LCT Cheung, MSc \\ ${ }^{4} \mathrm{ML}$ Ma, MNurs \\ ${ }^{5} \mathrm{EYW}$ Tse, MSC \\ ${ }^{6} \mathrm{TCM}$ Wong, $\mathrm{PhD}$ \\ ${ }^{7}$ PP Chen, FFPMANZCA
}

Department of Anaesthesia, Pamela Youde Nethersole Eastern Hospital, Chai Wan, Hong Kong

2 Hong Kong Sanatorium \& Hospital, Happy Valley, Hong Kong

${ }^{3}$ Department of Physiotherapy, Alice Ho Miu Ling Nethersole Hospital, Tai Po, Hong Kong

${ }^{4}$ Pain Management Centre, Alice Ho Miu Ling Nethersole Hospital, Tai Po, Hong Kong

${ }^{5}$ Department of Occupational Therapy, Alice Ho Miu Ling Nethersole Hospital, Tai Po, Hong Kong

${ }^{6}$ Department of Clinical Psychology, United Christian Hospital, Kwun Tong, Hong Kong

Department of Anaesthesiology and Operating Services, Alice Ho Miu Ling Nethersole Hospital, Tai Po, Hong Kong

* Corresponding author: chu0079@cuhk.edu.hk

New knowledge added by this study

- A programme of pain management based on cognitive behavioural principles is an effective treatment with potentially significant social savings for sufferers of chronic non-cancer pain in Hong Kong.

Implications for clinical practice or policy

- The pain programme is an effective treatment, and shall be a significant part of chronic pain rehabilitative services in Hong Kong.

\section{Introduction}

Chronic pain is a common condition that affects about $10 \%$ of the population in Hong Kong. ${ }^{1}$ Patients with chronic pain suffer a variety of physical and psychological co-morbidities, become medically dependent, and have significant loss of quality of life and work capacity. ${ }^{2}$

Pain management programmes based on cognitive behavioural principles have been recognised as an effective treatment for various chronic pain conditions. ${ }^{3}$ Such programmes are structured to incorporate a variety of rehabilitative strategies, with clearly defined physical, psychological, and social outcomes. Such concepts and practices are, however, largely unknown to the Chinese community.

In 2002, the Comprehensive Outpatient Pain Engagement (COPE) programme was established 
at the Alice Ho Miu Ling Nethersole Hospital, Hong Kong, with reference to the model of the Active Day Patient (ADAPT) programme at the University of Sydney, Australia. ${ }^{4}$ This is a 14 -day outpatient rehabilitation programme with 100 hours of clinical time per course. Core topics included education about pain pathophysiology, behavioural training with graded activities and exercises, pacing, relaxation, strengthening and stretching exercises, thought management, communication, as well as activity planning and appropriate use of medication. Individuals from multiple disciplines participated in the programme, including pain specialists, clinical psychologists, physiotherapists, occupational therapists, pain nurses, medical social workers, and hospital chaplains. To ensure consistency, all staff members were trained at the same Pain Management and Research Centre at the University of Sydney, and all courses were conducted according to a standardised timetable and protocol ${ }^{5}$ in use since its inception. From 2002 to 2012, 20 courses were conducted, with one to three courses per year, and eight to 12 participants per course.

An interim review in $2007^{5}$ demonstrated improved physical, psychological, and social functioning among participants up to 1 year after the programme. The major limitation of that report was the small number of subjects $(n=49)$. This report is an extended outcome study of the pain management programme. With more subjects, statistical significance should be improved.

\section{Methods}

All participants were recruited from the Pain Management Centre at the Alice Ho Miu Ling Nethersole Hospital, a tertiary referral centre in Hong Kong. They were patients with chronic noncancer pain, irrespective of site and diagnosis. ${ }^{5}$ They were assessed by the clinical psychologist, pain nurse, and pain specialist for eligibility to join the programme as a possible pain management option. Those with untreated psychiatric conditions, significant suicidal or homicidal risk, illiterate (either written or spoken Cantonese), and non-acceptance

\section{針對華籍患者的疼痛管理課程：十年結果回顧 朱銘知、羅家儀、張展庭、馬連、謝義偉、黃志明、曾煥涁} 目的：回顧香港疼痛管理課程的臨床和社會效益。

設計：前瞻性隊列研究。

安排：香港一所提供第三層醫療服務的門診部。

參與者：患有慢性非癌痛和長期受其影響（平均46個月）而於2002年 至2012年間參加綜合抗痛課程 (COPE) 的病人。

干預：在不論疼痛的原因或嚴重程度下為患者進行一個為期六星期的 門診疼痛復康課程, 旨在改善病者的功能以及減少因痛症而產生的障 礙。

主要結果測量：社會指標包括患者返回工作崗位的比率、住院和門診 人次。生理指標包括坐下和站立的耐力。心理指標如情緒、受苦感、 自我效能感、生活質量和認知績效。每位參與者均於參加 COPE前和 參加 $\mathrm{COPE}$ 一年後測量以上每項的結果。

結果：參加 $\mathrm{COPE}$ 後返回工作崗位的比率顯著改善, 由課程前 $17 \%$ 上 升至課程後 35\%（比值比 $=3.01$ ）；須醫療協助的比率也減低；生理 和心理指標均有改善。疼痛程度、心理壓力和工傷病史並不涉及返回 工作崗位的可能性。較短疼痛時間以及於SF36健康狀況調查簡表中的 身體機能分數較高者都是返回工作崗位的預後指標。

結論：縱然長時間受痛症影響, 參加COPE的慢性痛症患者其功能仍 能得到顯著改善。

to the therapy were not included in the study or the programme. Once recruited, prospective participants gave written informed consent for data collection and research, and agreement that medical treatment for pain control would remain unchanged until the programme commenced. On completion of the programme, routine follow-ups were arranged for up to 1 year.

A standardised set of measurements (Table $\left.1^{6-10}\right)$ was used to assess the physical, psychological, and social functioning on the first day of the programme, and 12 months after each course. These measurements were self-reporting, self-administered questionnaires commonly used among pain clinics in Hong Kong and staff were familiar with the measurement tools. All measurements were made in Chinese and were validated in the local setting.

TABLE I. Statistics of outcome parameters $\mathrm{s}^{6-10}$

\begin{tabular}{ll}
\hline Parameter & Test/description \\
\hline Pain intensity & Numerical Rating Scale \\
Affect & Hospital Anxiety and Depression Scale: Anxiety and Depression subscales ${ }^{6}$ \\
Cognitions & $\begin{array}{l}\text { Pain Catastrophizing Scale } \\
\text { Patient Self-Efficacy Questionnaire score }\end{array}$ \\
\hline Daily activities & Canadian Occupational Performance Measure: Performance and Satisfaction subscales ${ }^{8}$ \\
\hline $\begin{array}{l}\text { Power and endurance } \\
\text { Quality of life }\end{array}$ & Standing and sitting tolerances (minutes) timers, self-measured \\
\hline Work status & 36-Item Short-Form Health Survey ${ }^{10}$ \\
\hline Medical utilisation & Working (full- or part-time) or not working (volunteering, retirement, studying, sick leave) \\
\hline
\end{tabular}


TABLE 2. Demographics of participants who completed the pain programme $(n=\mid 42)$

\begin{tabular}{|c|c|}
\hline Characteristic & Data* \\
\hline Sex (male / female) & $57 / 85$ \\
\hline Age (years) & $42.0(21-62)$ \\
\hline Duration of pain (months) & $46.1(4-216)$ \\
\hline Injury at work & $97(68.3 \%)$ \\
\hline \multicolumn{2}{|l|}{ Site of pain } \\
\hline Low back & $57(40.1 \%)$ \\
\hline Neck & $6(4.2 \%)$ \\
\hline Limbs & $8(5.6 \%)$ \\
\hline Others & $13(9.2 \%)$ \\
\hline Multiple sites & 58 (40.8\%) \\
\hline
\end{tabular}

TABLE 3. Physical and psychological outcomes

\begin{tabular}{|c|c|c|c|}
\hline \multirow[t]{2}{*}{ Outcome } & \multicolumn{2}{|c|}{ Mean (standard deviation) } & \multirow{2}{*}{$\begin{array}{c}P(\text { or } Z) \\
\text { value }\end{array}$} \\
\hline & Baseline & 1 Year & \\
\hline Sitting tolerance (mins) & $14.9(8.6)$ & $35.6(30.3)$ & $<0.001$ \\
\hline Standing tolerance (mins) & $10.8(8.1)$ & $30.0(40.2)$ & $<0.001$ \\
\hline HADS-depression & $11.9(4.4)$ & $10.4(5.24)$ & 0.001 \\
\hline HADS-anxiety & $11.0(4.5)$ & $10.0(4.8)$ & 0.029 \\
\hline PCS & $34.1(11.1)$ & $25.8(14.1)$ & $<0.001$ \\
\hline PSEQ & $23.2(11.0)$ & $30.6(13.9)$ & $<0.001$ \\
\hline COPM-satisfaction & $3.4(1.5)$ & $6.2(2.1)$ & $<0.001$ \\
\hline COPM-performance & $3.4(1.3)$ & $5.9(1.9)$ & $<0.001$ \\
\hline SF36-physical functioning & $40.4(17.3)$ & $46.3(21.8)$ & $<0.001$ \\
\hline SF36-role physical & $2.3(8.5)$ & $17.1(31.1)$ & $<0.001$ \\
\hline SF36-bodily pain & $21.2(12.4)$ & $27.4(16.9)$ & $<0.001$ \\
\hline SF36-general health & $21.4(18.1)$ & $36.7(23.0)$ & 0.030 \\
\hline SF36-vitality & $29.9(15.4)$ & $36.7(20.8)$ & $<0.001$ \\
\hline SF36-social functioning & $33.2(17.5)$ & $43.1(25.9)$ & $<0.001$ \\
\hline SF36-role emotional & $13.5(27.4)$ & $22.6(36.9)$ & 0.007 \\
\hline SF36-mental health & $43.4(20.5)$ & $47.3(22.2)$ & 0.049 \\
\hline Pain-intensity NRS & $6.2(1.5)$ & $6.0(1.7)$ & 0.153 \\
\hline
\end{tabular}

Abbreviations: $\mathrm{COPM}=$ Canadian Occupational Performance Measure; HADS = Hospital Anxiety and Depression Scale; NRS = Numerical Rating Scale; PCS = Pain Catastrophizing Scale; PSEQ = Patient Self Efficacy Questionnaire; SF36 = 36-Item Short-Form Health Survey

Medical records of every participant were reviewed 1 year before and after the programme for history of injury, work status, pain-related admissions, or outpatient consultations.

Demographic and pain information were presented as descriptive statistics. Paired $t$ test, Wilcoxon signed rank test, and contingency table with Fisher's exact test were used to evaluate the overall effectiveness of the programme. Logistic regression predicting 12-month return-to-work status was performed with a history of injury at work, age, duration of pain, and the 36-Item ShortForm Health Survey (SF36) physical functioning as covariates using the 'enter' regression method. The Statistical Package for the Social Sciences (Windows version 10.0; SPSS Inc, Chicago [IL], US) was used for the calculations. A level of significance of $\mathrm{P}$ or $\mathrm{Z}<0.05$ was accepted for the study.

This study was approved by the local ethics committee (Joint CUHK-NTEC Clinical Research Ethics Committee CREC2013.205).

\section{Results}

From 2002 to 2012, up to 4000 new cases of chronic pain were assessed at the clinic, and 158 patients were recruited. The exact number of patients for each of the exclusion criterion was unknown. Over the years, 14 participants withdrew during the course, and two defaulted from post-programme reviews. A total of 142 participants completed the course (Table 2).

There was a significant improvement in all of the physical and psychological parameters 1 year after the programme despite a long history (mean, 46 months) of signs and symptoms before the programme (Table 3). Despite similar pain-intensity ratings, functional tolerance (such as sitting and standing) had more than doubled. Depression, anxiety, and catastrophisation (psychological tendency to ruminate and magnify negative aspects of pain and health) scores were reduced. Self-efficacy, perceived performance and satisfaction with daily activities, and quality-of-life scores had improved. All changes were statistically significant $(\mathrm{P}<0.05)$.

There was also a considerable improvement in work status (Table 4). Of the 142 participants, only $24(17 \%)$ were working before the programme. The work statuses of 129 participants were known after the programme, of whom $49(35 \%)$ were in work (including 28 who were not working before the programme). The odds ratio (OR) of participants working after the programme versus before was 3.01 (95\% confidence interval, 1.71-5.30; $\mathrm{P}=0.0002$ ). Further analysis of the 106 patients who were not working initially revealed that baseline pain intensity was similar among those who returned to work and those who did not (Table 5). There were also no statistically significant differences in the psychological and physical parameters except a higher SF36 physical functioning score (47.5 vs 39.0). Other significant differences included younger age (39.1 vs 44.0 years) and shorter duration of pain (28.3 vs 50.5 months) among those who returned to work. History of injury at work was also more common in this group $(\mathrm{OR}=3.36$, Table 4). Logistic regression on these four significant variables predicting 12-month return-to-work status showed that duration of pain $(\mathrm{OR}=0.955, \mathrm{P}=0.020)$ and $\mathrm{SF} 36$ physical functioning $(\mathrm{OR}=1.041, \mathrm{P}=0.002)$ were significant independent 
predictors, while history of injury at work and age were not (Table 6).

Utilisation of medical resources was also significantly reduced after the programme: average out-patient attendance (visits per person per year) reduced from 7.95 to 6.39 , and hospitalisation (admissions per person per year) reduced from 0.59 to 0.21 . All changes were statistically significant $(\mathrm{P}<0.05)$.

\section{Discussion}

The COPE programme is one of the first pain programmes for psychosocial rehabilitation of patients with chronic non-cancer pain in a Chinese community. As the concepts of self-management, active coping, and functional improvement despite pain were new to the local patients and staff, it took a considerable effort to train staff and encourage local patients to join the programme. The slow recruitment prevented the authors from performing any randomised trial, and the sample size was statistically unrepresentative of the local chronic pain caseload (up to 400 new cases per year, recruitment rate of approximately $4 \%$ ). Some important information, such as reasons for exclusion from the programme, were not included in the database. Selection bias might further limit the usefulness of the information.

Despite the limitations, the results demonstrated an all-round positive outcome for patients who completed the programme. The programme was not designed for pain reduction and indeed the pain intensity never changed, yet the participants became less fearful about pain and movement, and were able to continue to function despite the pain. The skills learnt in the programme were simple, self-managing, did not require special equipment or medications, and participants were encouraged to solve problem and adopt these skills in their own social setting. As the participants managed to see the dissociation between pain and disability, they become motivated to apply these skills continuously. This may have contributed to the lasting improvement.

The social improvement was very encouraging. Not only was there a lasting reduction in utilisation of medical resources, it came as a pleasant surprise that about one quarter of non-working participants
TABLE 4. Work status at baseline and 12 months after the pain programme, and history of injury at work among the non-working participants before the programme, according to work status at I year after the programme

\begin{tabular}{lcc}
\hline & Working & Not working \\
\hline Work status $(n=142)$ & & \\
At baseline & $24(17 \%)$ & $118(83 \%)$ \\
12 Months after the programme* & $49(35 \%)$ & $80(56 \%)$ \\
History of injury at work $(n=106) \dagger$ & $(n=28)$ & $(n=78)$ \\
Yes & $24(86 \%)$ & $50(64 \%)$ \\
No & $4(14 \%)$ & $28(36 \%)$ \\
\hline
\end{tabular}

* Data were missing for 13 (9\%) patients, and 3 working patients retired after the programme

+ Odds ratio=3.36 (95\% confidence interval I.06-10.67); $P<0.05$

TABLE 5. Physical and psychological measurements of non-working participants before the programme, according to work status at I year after the programme $(n=106)$

\begin{tabular}{|c|c|c|c|}
\hline & \multicolumn{2}{|c|}{ Mean (standard deviation) } & \multirow{2}{*}{$\begin{array}{c}P \text { (or } Z \text { ) } \\
\text { value }\end{array}$} \\
\hline & Working $(n=28)$ & Not working $(n=78)$ & \\
\hline Age (years) & $39.1(8.5)$ & $44.0(8.2)$ & 0.013 \\
\hline Duration of pain (months) & $28.3(13.3)$ & $50.5(39.3)$ & 0.003 \\
\hline Sitting tolerance (mins) & $13.8(7.6)$ & $15.2(9.3)$ & 0.637 \\
\hline Standing tolerance (mins) & $10.7(7.8)$ & $10.3(8.6)$ & 0.7 \\
\hline HADS-depression & $11.0(4.9)$ & $12.1(4.1)$ & 0.302 \\
\hline HADS-anxiety & $10.9(5.1)$ & $10.8(4.2)$ & 0.796 \\
\hline PCS & $33.3(12.3)$ & $33.9(10.8)$ & 0.923 \\
\hline PSEQ & $25.0(11.7)$ & $23.0(11.1)$ & 0.211 \\
\hline COPM-satisfaction & $5.7(1.8)$ & $5.9(1.8)$ & 0.234 \\
\hline COPM-performance & $5.7(1.7)$ & $5.8(1.6)$ & 0.651 \\
\hline SF36-physical functioning & $47.5(16.1)$ & $39.0(17.5)$ & 0.013 \\
\hline SF36-role physical & $3.6(11.2)$ & $2.6(9.5)$ & 0.625 \\
\hline SF36-bodily pain & $22.9(13.3)$ & $21.5(12.8)$ & 0.828 \\
\hline SF36-general health & $34.1(20.4)$ & $33.7(17.2)$ & 0.746 \\
\hline SF36-vitality & $32.1(17.5)$ & $28.9(15.1)$ & 0.293 \\
\hline SF36-social functioning & $35.5(16.6)$ & $31.7(17.8)$ & 0.201 \\
\hline SF36-role emotional & $13.1(26.2)$ & $14.5(28.8)$ & 0.973 \\
\hline SF36-mental health & $43.4(26.2)$ & $42.7(18.4)$ & 0.937 \\
\hline Pain intensity NRS & $6.0(1.5)$ & $6.2(1.7)$ & 0.186 \\
\hline
\end{tabular}

Abbreviations: COPM = Canadian Occupational Performance Measure; HADS = Hospital Anxiety and Depression Scale; NRS = Numerical Rating Scale; PCS = Pain Catastrophizing Scale; PSEQ = Patient Self Efficacy Questionnaire; SF36 = 36-Item Short-Form Health Survey

TABLE 6. Logistic regression predicting return-to-work status for non-working participants before the programme $(n=106)$

\begin{tabular}{lcccc}
\hline Predictor & B & Wald statistic & P value & Odds ratio (95\% confidence interval) \\
\hline History of injury at work & 0.492 & 0.447 & 0.504 & $1.635(0.387-6.907)$ \\
Age & -0.048 & 2.435 & 0.119 & $0.953(0.898-1.012)$ \\
Duration of pain & -0.046 & 5.450 & 0.020 & $0.955(0.919-0.993)$ \\
SF36 physical functioning & 0.040 & 9.577 & 0.002 & $1.041(1.015-1.067)$ \\
\hline
\end{tabular}

Abbreviation: SF36 = 36-Item Short-Form Health Survey 
were able to resume work. This is remarkable as this was a cohort with very long duration of pain, with most of the participants out of work for more than 2 years. It would also have been an unfavourable course of prolonged work absenteeism for patients with musculoskeletal pain and work-related injuries. ${ }^{11-13}$ Our post-hoc analysis reconfirmed that it remained a significant prognostic indicator of vocational outcome even after years of disability. As work was such an important outcome for the patient and the society, it would be useful to examine if early intervention could generate better return-to-work outcomes.

Another interesting finding was that most of the biological and psychological parameters were not associated with vocational outcome after the programme. In other words, while the psychological 'yellow flags' might be useful in chronic pain and disability prognosis, ${ }^{14}$ they might not be predictive of vocational outcome among this cohort of subjects. Apart from the long duration, our cohort of patients was characterised by very low quality-of-life scores in multiple domains. The poor psychological profile might have rendered most psychological measurements less discriminative than reported elsewhere. ${ }^{15}$ The only significant psychological prognostic indicator was a higher SF36 physical functioning score. This domain was known to have the strongest association with return-towork among all the SF36 domains for subjects with chronic back pain, ${ }^{15}$ and stood out among other less discriminative domains for predicting outcome. Other prognostic factors, such as the patients' expectation, social background, occupational 'blue flags' and the contextual 'black flags', might be in place and need further exploration. ${ }^{16-18}$ The economy might have also contributed to the favourable vocational outcome. However, the annual drop in unemployment (approximately 1\%) during the period ${ }^{19}$ was much lower than the observed increase in work rate at 1 year (18\%), and was probably a minor contribution to the overall improvement. The relationship between compensable injuries and return to work is much debated. Our data suggested that history of injury at work might have been an associating rather than independent variable in vocational outcome, with other confounding factors such as age or SF36. During each programme, the long-term goal setting would include a discussion on the impact of litigation and compensation on returning to work and may have reduced their potential detrimental effects.

Our findings provide a comparison with those from other non-cancer pain rehabilitation programmes in Hong Kong. In 2010, Luk et $\mathrm{al}^{20}$ published their rehabilitation programme outcome for patients with chronic low back pain. Following almost 400 hours of physiotherapy and occupational therapy, physical function improved although mood remained unchanged at 6 months. ${ }^{20}$ Approximately $52 \%$ of the participants returned to work 6 months after the programme. ${ }^{20}$ Those who returned to work showed a reduction in perceived disability, pain intensity, better physical performance, and similar mood compared with those who did not. ${ }^{20}$ The apparent discrepancy between Luk et al's study ${ }^{20}$ and our study was due to differences in patient cohort and programme design. In Luk et al's study, ${ }^{20}$ the average pain history was 22 months. These parameters compared favourably with our cohort of mean pain history of 46 months. Patients were referred from different sources (orthopaedics and pain clinics) with a different demographic (predominantly male in Luk et al's group ${ }^{20}$ vs predominantly female in ours) and disease profile (exclusively back patients in Luk et al's group ${ }^{20}$ vs heterogeneous in ours). The duration of therapy was almost 4 times longer in Luk's study, ${ }^{20}$ allowing ample time for work strengthening and vocational training. On the contrary, our programme was designed for general rehabilitation and offered no vocational training. The comparison demonstrated the wide variety of presentation of pain patients, and the spectrum of therapies available in Hong Kong with different objectives and emphasis. Nonetheless both studies were in agreement that duration of absence from work was unanimously identified as a prognostic indicator for return to work.

In 2012, Tse et $\mathrm{al}^{21}$ published their outcome report of a pain management programme for chronic non-cancer pain among elderly home residents. Over 290 elderly subjects enrolled in the 8-week programme with physical exercises and multisensory art and craft therapy, together with pain education for their carer. The pain intensity in some areas (back and multiple joints) was significantly reduced after the programme, together with increased range of motion in all joints, and improvement in selected mood measurements. Perceived quality of life, as measured by SF12, did not differ significantly after the programme. There were no data on physical function, pain cognition, and social consequences. As the patient group and the programme design and outcome measurements were radically different to our study and that of Luk et al, ${ }^{20}$ results could not be compared nor conclusions drawn.

The practice of a multidisciplinary pain programme has also begun recently in Asia. In 2012, Cardosa et $\mathrm{al}^{22}$ reported a series of 120 patients who underwent the MENANG programme in Malaysia, a programme based on the same model (the ADAPT programme) as ours. Despite the differences in ethnicity, language and religion, the physical and psychological improvement was comparable to that of patients from Australia and Hong Kong. The efficacy was maintained despite the modifications made in both Asian programmes to adapt to the local 
culture and customs. The challenges of organising a pain programme were clearly felt by both Asian groups, as the small sample sizes suggest.

There are significant limitations to this study. The small sample size recruited from one single centre made it difficult to extrapolate the findings to another local chronic pain population. This was also an observational study although data were collected prospectively, and there was no control therapy group for comparison. The data set were primarily physical and psychological constructs, and some important social factors associated with return to work were not collected (such as the 'blue flag' factors) and included in the analyses, hence confounding was possible. There was also a lack of information about those who were excluded from the programme and why, thus significant selection (and self-selection) bias is present. Prospective randomised controlled trials are needed to confirm the effectiveness of the programme, or to compare the efficacy of different programmes with different designs.

\section{Conclusions}

The cognitive behavioural-based pain management programme improved quality of life and reduced disability for selected patients with chronic noncancer pain in Hong Kong. More patients returned to work after the programme, and they consumed less medical resources, with potentially significant social savings. The strongest association with returning to work was a brief duration of pain rather than the baseline intensity of pain, compensable injuries, physical impairment, or psychological distress of the subject.

\section{Acknowledgements}

The authors would like to thank the multidisciplinary pain management team at the Alice Ho Miu Ling Nethersole Hospital, and the Pain Management and Research Centre at the University of Sydney for their assistance in the development of the COPE programme, data collection, and manuscript preparation.

\section{References}

1. Ng KF, Tsui SL, Chan WS. Prevalence of common chronic pain in Hong Kong adults. Clin J Pain 2002;18:275-81.

2. Blyth FM, March LM, Nicholas MK, Cousins MJ. Chronic pain, work performance and litigation. Pain 2003;103:41-7.

3. Chou R, Huffman LH; American Pain Society; American College of Physicians. Nonpharmacologic therapies for acute and chronic low back pain: a review of the evidence for an American Pain Society/American College of Physicians clinical practice guideline. Ann Intern Med 2007;147:492-504.

4. Nicholas M, Molloy A. Manage your pain: practical and positive ways of adapting to chronic pain. Australia: ABC Books; 2001.

5. Man AK, Chu MC, Chen PP, Ma M, Gin T. Clinical experience with a chronic pain management programme in Hong Kong Chinese patients. Hong Kong Med J 2007;13:372-8.

6. Leung CM, Wing YK, Kwong PK, Lo A, Shum K. Validation of the Chinese-Cantonese version of the hospital anxiety and depression scale and comparison with the Hamilton Rating Scale of Depression. Acta Psychiatr Scand 1999;100:456-61.

7. Yap JC, Lau J, Chen PP, et al. Validation of the Chinese Pain Catastrophizing Scale (HK-PCS) in patients with chronic pain. Pain Med 2008;9:186-95.

8. Lim HS, Chen PP, Wong TC, et al. Validation of the Chinese version of pain self-efficacy questionnaire. Anesth Analg 2007;104:18-23.

9. Carpenter L, Baker GA, Tyldesley B. The use of the Canadian occupational performance measure as an outcome of a pain management program. Can J Occup Ther 2001;68:16-22.

10. Lam CL, Gandek B, Ren XS, Chan MS. Tests of scaling assumptions and construct validity of the Chinese (HK) version of the SF-36 Health Survey. J Clin Epidemiol 1998;51:1139-47.

11. Frank JW, Brooker A, DeMaio SE, et al. Disability resulting from occupational low back pain: Part II: What do we know about secondary prevention? A review of the scientific evidence on prevention after disability begins. Spine (Phila Pa 1976) 1996;21:2918-29.

12. Lötters F, Burdorf A. Prognostic factors for duration of sickness absence due to musculoskeletal disorders. Clin J Pain 2006;22:212-21.

13. Cheng AS, Hung LK. Socio-demographic predictors of work disability after occupational injuries. Hong Kong J Occup Ther 2007;17:45-53.

14. Buck R, Barnes MC, Cohen D, Aylward M. Common health problems, yellow flags and functioning in a community setting. J Occup Rehabil 2010;20:235-46.

15. Gatchel RJ, Mayer T, Dersh J, Robinson R, Polatin P. The association of the SF-36 health status survey with 1-year socioeconomic outcomes in a chronically disabled spinal disorder population. Spine (Phila Pa 1976) 1999;24:2162-70.

16. Kuijer W, Groothoff JW, Brouwer S, Geertzen JH, Dijkstra PU. Prediction of sickness absence in patients with chronic low back pain: a systematic review. J Occup Rehabil 2006;16:439-67.

17. Iles RA, Davison M, Taylor NF. Psychosocial predictors of failure to return to work in non-chronic non-specific low back pain: a systematic review. Occup Environ Med 2008;65:507-17.

18. Buck R, Porteous C, Wynne-Jones G, Marsh K, Phillips CJ, Main CJ. Challenges to remaining at work with common health problems: what helps and what influence do organisational policies have? J Occup Rehabil 2011;21:501-12.

19. Hong Kong unemployment rate. Available from: http:// www.tradingeconomics.com/hong-kong/unemploymentrate. Accessed 26 Sep 2014.

20. Luk KD, Wan TW, Wong YW, et al. A multidisciplinary rehabilitation programme for patients with chronic low back pain: a prospective study. J Ortho Surg (Hong Kong) 2010;18:131-8.

21. Tse MM, Vong SK, Ho SS. The effectiveness of an integrated pain management program for older persons and staff in nursing homes. Arch Gerontol Geriatr 2012;54:e203-12.

22. Cardosa M, Osman ZJ, Nicholas M, et al. Self-management of chronic pain in Malaysian patients: effectiveness trial with 1-year follow up. Transl Behav Med 2012;2:30-7. 